\title{
Rainfall Estimation from Polarimetric Radar Measurements: Composite Algorithms Immune to Variability in Raindrop Shape-Size Relation
}

\author{
Eugenio Gorgucci AND Gianfranco SCARCHILli \\ Istituto di Fisica dell'Atmosfera, Rome, Italy \\ V. Chandrasekar AND V. N. BRINGI \\ Department of Electrical Engineering, Colorado State University, Fort Collins, Colorado
}

(Manuscript received 6 June 2000, in final form 21 March 2001)

\begin{abstract}
Polarization diversity radar measurements such as reflectivity factor, differential reflectivity, and differential propagation phase are extensively used in rainfall estimation. Algorithms to estimate rainfall from polarimetric radar measurements are based on a model for the raindrop shape as a function of drop diameter. Most of the current algorithms use an equilibrium shape-size model for raindrops. Variation of the prevailing mean raindrop shapes from an assumed model has a direct impact on the accuracy of radar rainfall estimates. This paper develops composite algorithms to estimate rainfall from polarimetric radar data without an a priori assumption about the specific form of mean raindrop shape-size model such as equilibrium shape model. The accuracy of rainfall estimates is evaluated in the presence of random measurement errors as well as systematic bias errors. The composite algorithms, independent of a prespecified raindrop shape model, were applied to radar parameters simulated from disdrometer data collected over 3 months, and the corresponding rainfall estimates were found to be in good agreement with disdrometer estimates. The composite algorithms were also tested with Colorado State University CHILL radar observations of the 28 July 1997 Fort Collins (Colorado) flood event. The storm total precipitation estimates based on the composite algorithms developed in this paper were in much better agreement with rain gauge estimates in comparison with conventional algorithms.
\end{abstract}

\section{Introduction}

Polarization diversity radar measurements for rainfall estimation have been studied for nearly two decades. The research results to date have been sufficient to consider polarimetric upgrades to operational WSR-88D radars (Doviak et al. 2000). The most commonly used polarimetric radar measurements in rainfall estimation are the reflectivity factor, usually at horizontal polarization $\left(Z_{h}\right)$, differential reflectivity $\left(Z_{\mathrm{dr}}\right)$, and specific differential propagation phase $\left(K_{\mathrm{dp}}\right)$. Based on the above three measurements, a number of algorithms have been derived in the literature to estimate rainfall (Seliga and Bringi 1976; Sachidananda and Zrnić 1987; Chandrasekar et al. 1990; Gorgucci et al. 1994; Ryzhkov and Zrnić 1995; Gorgucci and Scarchilli 1997). These algorithms have been derived assuming equilibrium raindrop shapes, described by a shape-size relationship (Pruppacher and Beard 1970). The mean axis ratio versus size relation is crucial for deriving algorithms that

Corresponding author address: Dr. Eugenio Gorgucci, Istituto di Fisica dell'Atmosfera, Area di Ricerca Roma-Tor Vergata, Via del Fosso del Cavaliere, 100, 00133 Roma, Italy.

E-mail: Gorgucci@radar.ifa.rm.cnr.it use $Z_{\mathrm{dr}}$ and $K_{\mathrm{dp}}$ (Jameson 1983, 1985). A recent study by Keenan et al. (1997) indicates that $K_{\mathrm{dp}}$-based polarimetric radar rainfall algorithms are influenced by deviation from the equilibrium shape of raindrops. Thus, it would be important to derive an algorithm to estimate rainfall rate that is made immune to variability in the mean raindrop shape-size relationship. Gorgucci et al. (2000a) demonstrated that the slope of a linear mean raindrop shape-size relation can be estimated from polarimetric radar measurements. In principle, if the mean shape-size relation for raindrops is known then the rainfall rate can be estimated accurately. Therefore, the goal of this paper is to incorporate the results of Gorgucci et al. (2000a) into rainfall estimation algorithms so that the algorithms can be used for any prevailing mean raindrop shape without any prior assumption of the shape-size model. This paper presents composite algorithms to estimate rainfall rate using polarimetric radar measurements that are independent of any variability in the mean raindrop shape-size relations.

The paper is organized as follows: section 2 describes the various polarimetric radar rainfall algorithms, section 3 describes the effect of variability in the mean raindrop shape on radar rainfall algorithms, and section 


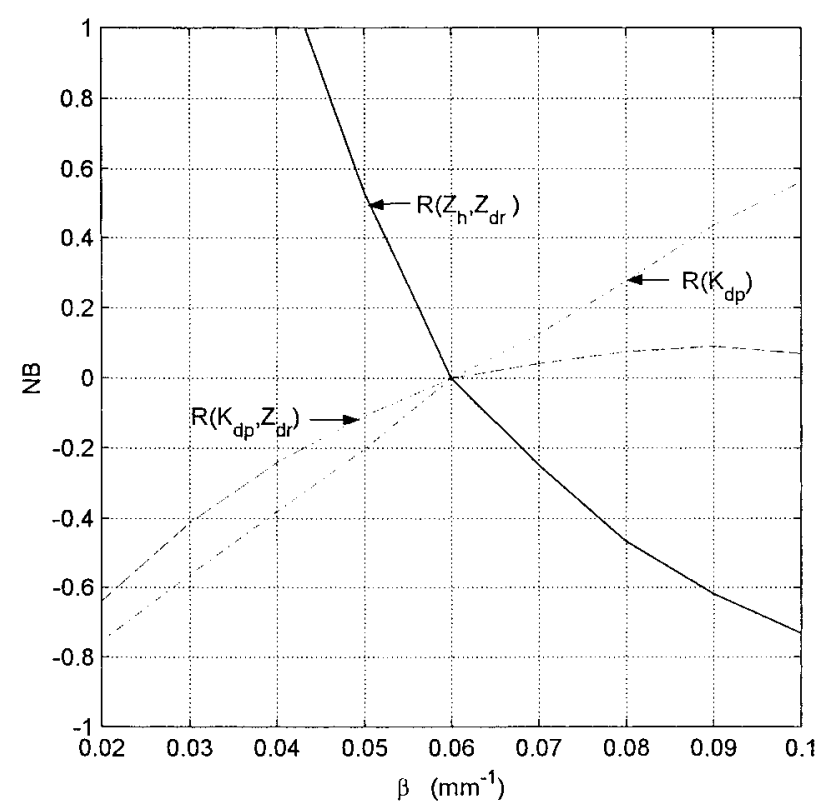

FIG. 1. Normalized bias (NB) of $R\left(Z_{h}, Z_{\mathrm{dr}}\right), R\left(K_{\mathrm{dp}}\right)$, and $R\left(K_{\mathrm{dp}}, Z_{\mathrm{dr}}\right)$ as a function of $\beta$. The algorithms were derived for $\beta=\beta_{e}=0.062$, however applied to all $\beta$. Note that when $\beta=\beta_{e}$ bias is 0 .

4 describes the development of radar rainfall algorithms, which are independent of the mean raindrop shape-size relationship. The performance of the new algorithms in the presence of nonlinear models for the raindrop shapesize relation is presented in section 5 . The corresponding error structure and sensitivity of the radar rainfall algorithms developed in section 4 is described in section 6. Section 7 presents evaluation of the algorithms developed in this paper using disdrometer data collected in Darwin (Australia) as well as radar and rain gauge data collected in a flash flood producing storm using the Colorado State University (CSU) CHILL (CSUCHILL) radar. Section 8 summarizes the important results of this paper.

\section{Polarimetric radar measurements and rainfall algorithms}

The distribution of raindrop sizes and shapes determines the electromagnetic scattering properties of rainfilled media. These effects, in turn, are embodied in radar measurements such as, reflectivity factors $\left(Z_{h, v}\right)$ at $h$ and $v$ polarization states, differential reflectivity $\left(Z_{\mathrm{dr}}\right)$, which is the ratio of reflectivities at the two polarization states (Seliga and Bringi 1976), and specific differential phase $\left(K_{\mathrm{dp}}\right)$, which is due to the propagation phase difference between the two polarizations (Seliga and Bringi 1978; Sachidananda and Zrnić 1987). Both cloud models and measurements of raindrop size distributions (RSD) at the surface and aloft show that a gamma distribution model adequately describes many of the natural variations in the RSD (Ulbrich 1983):

$$
N(D)=n_{c} f(D) \quad\left(\mathrm{m}^{-3} \mathrm{~mm}^{-1}\right),
$$

where $N(D)$ is the number of the raindrops per unit volume per unit size interval ( $D$ to $D+\Delta D$ ), $n_{c}$ is the concentration, and $f(\mathrm{D})$ is the gamma probability density function (pdf) given by

$$
f(D)=\frac{\Lambda^{\mu+1}}{\Gamma(\mu+1)} e^{-\Lambda D} D^{\mu} ; \quad \mu>-1,
$$

where $\Lambda$ and $\mu$ are parameters of the gamma pdf and $\Gamma$ indicates gamma function (Abramovitz and Stegun 1970). The volume-weighted median diameter $D_{0}$ can be defined as

$$
\int_{0}^{D_{0}} D^{3} N(D) d D=\int_{D_{0}}^{\infty} D^{3} N(D) d D .
$$

The parameter $\mathrm{N}_{0}$ defined by Ulbrich (1983) is related to $n_{c}$ by

$$
n_{c}=\frac{N_{0} \Gamma(\mu+1)}{\Lambda^{\mu+1}} .
$$

An alternate form of normalizing the RSD with respect to water content can be written as (Willis 1984; Illingworth and Blackman 1999; Testud et al. 2000)

$$
N(D)=N_{w} f(\mu)\left(\frac{D}{D_{0}}\right)^{\mu} \exp (-\Lambda D)
$$

where

$$
\begin{aligned}
N_{0} & =N_{w} f(\mu) D_{0}^{-\mu}, \text { and } \\
f(\mu) & =\frac{6}{3.67^{4}} \frac{(3.67+\mu)^{\mu+4}}{\Gamma(\mu+4)} .
\end{aligned}
$$

The equilibrium shape of a raindrop is determined by the balance between the forces due to surface tension, hydrostatic pressure, and aerodynamic pressure from airflow around the drop. Raindrop shapes have been extensively studied (e.g., see the review by Pruppacher and Klett 1997). A few relevant references are the theoretical studies by Green (1975) and Beard and Chuang (1987), the experimental studies by Pruppacher and Beard (1970), and axis ratio measurements in natural rainfall using aircraft imaging probes by Chandrasekar et al. (1988) and Bringi et al. (1998). All these studies as well as polarimetric radar measurements show that the raindrop shapes can be approximated by an oblate spheroid with the axis ratio $(b / a)$ given as

$$
r=\frac{b}{a}=1.03-\beta D,
$$

where $D$ is the equivolumetric spherical diameter (typically in units of $\mathrm{mm}$ ); $a$ and $b$ are the major and minor axes of the spheroid, respectively; and $\beta$ is the slope given by

$$
\beta=-\frac{d r}{d D}
$$


a)

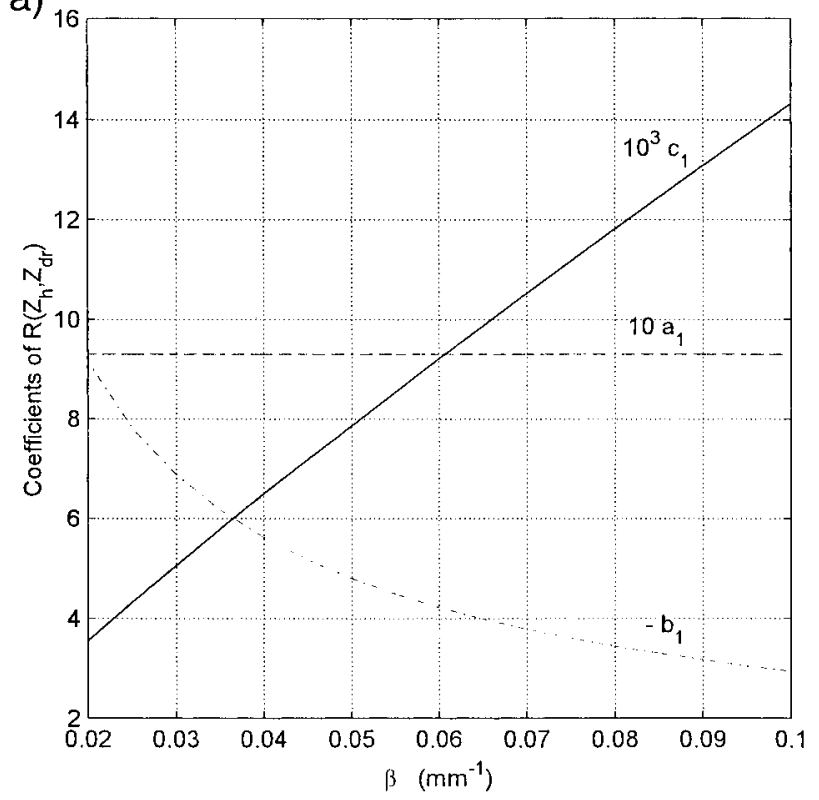

c)

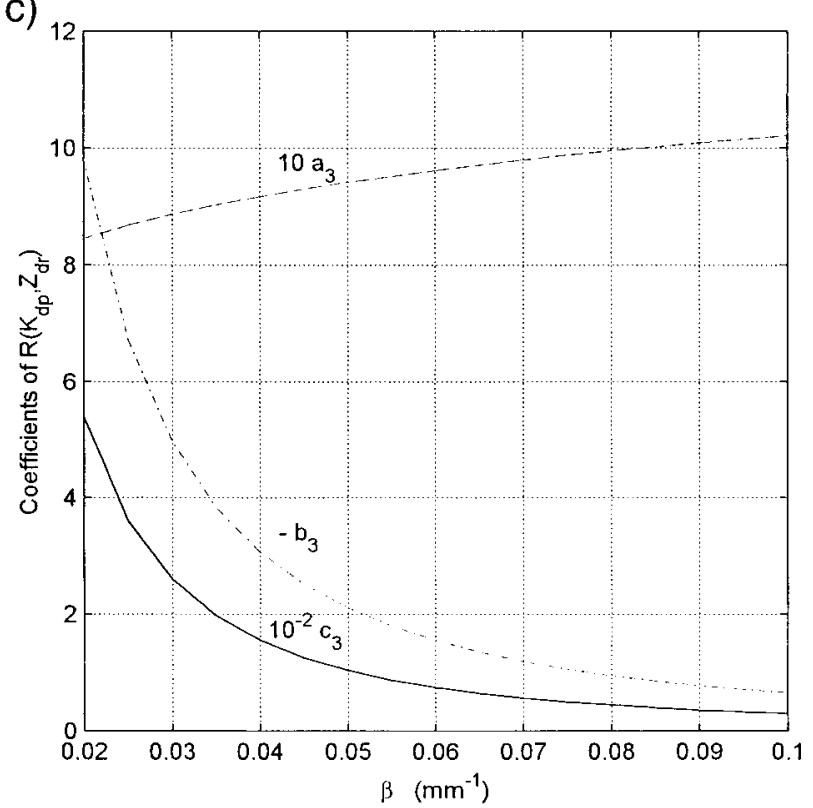

b)

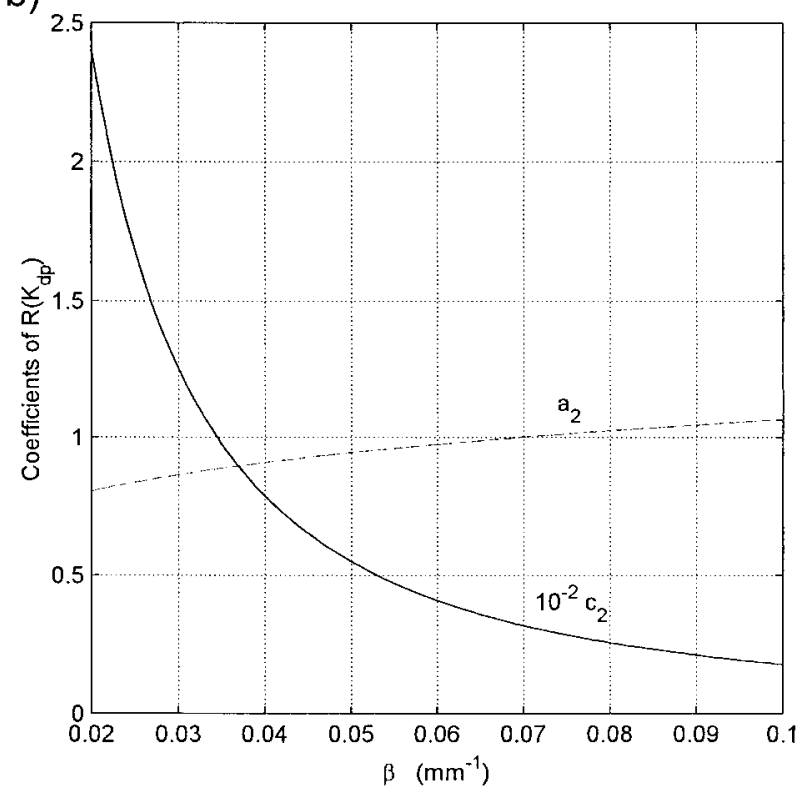

FIG. 2. (a) The coefficients $c_{1}, a_{1}, b_{1}$ of $R\left(Z_{h}, Z_{\mathrm{dr}}\right)$ algorithm given as a function of $\beta$. (b) The coefficients $c_{2}, a_{2}$ of $R\left(K_{\mathrm{dp}}\right)$ algorithm given as a function of $\beta$. (c) The coefficients $c_{3}, a_{3}, b_{3}$ of $R\left(K_{\mathrm{dp}}, Z_{\mathrm{dr}}\right)$ algorithm given as a function of $\beta$.

A commonly used value for $\beta$ is 0.062 , which is a linear fit to the wind tunnel data of Pruppacher and Beard (1970) (henceforth referred to as PB). When $\beta=0.062$ in (5), it corresponds to a representative approximation of the equilibrium shape-size relation, and henceforth is denoted by $\beta_{e}$. It should be noted here that some raindrop shape models such as the one described by Beard and Chuang (1987) (henceforth referred to as $\mathrm{BC}$ ), and the one described by Andsager et al. (1999) (henceforth referred to as ABL) are not linear shape- size relations but third degree polynomials of the drop diameter. In particular, the ABL model attempts to synthesize the effects of raindrop oscillations for drops in the range $1-4 \mathrm{~mm}$ using both laboratory axis ratio data as well as field measurements. In this paper, it is assumed that the linear relation in (5) and the corresponding slope $\beta$ can effectively account for raindrop oscillations.

The radar observables, namely, $Z_{h, v}, Z_{\mathrm{dr}}$, and $K_{\mathrm{dp}}$, can be expressed in terms of the RSD as follows: 


$$
Z_{h, v}=\frac{\lambda^{4}}{\pi^{5}|k|^{2}} \int \sigma_{h, v}(D) N(D) d D \quad\left(\mathrm{~mm}^{6} \mathrm{~m}^{-3}\right),
$$

where $\sigma_{h, v}$ represent the radar cross sections at horizontal and vertical polarizations, respectively; $\lambda$ the wavelength; and $k=\left(\epsilon_{r}-1\right) /\left(\epsilon_{r}+2\right)$, where $\epsilon_{r}$ is the dielectric constant of water;

$$
\begin{aligned}
& Z_{\mathrm{dr}}=10 \log \left[\frac{\int \sigma_{h}(D) N(D) d D}{\int \sigma_{v}(D) N(D) d D}\right] \text { and } \\
& K_{\mathrm{dp}}=\frac{180 \lambda}{\pi} \Re \int\left[f_{h}(D)-f_{v}(D)\right] N(D) d D \\
& \left({ }^{\circ} \mathrm{km}^{-1}\right),
\end{aligned}
$$

where $\Re$ refers to real part of a complex number and $f_{h}$ and $f_{v}$ are the forward-scatter amplitudes at $h$ and $v$ polarization, respectively. Radar measurements used in polarization diversity radar estimates of rainfall rate are $Z_{h}\left(\mathrm{~mm}^{6} \mathrm{~m}^{-3}\right), Z_{\mathrm{dr}}(\mathrm{dB})$, and $K_{\mathrm{dp}}\left({ }^{\circ} \mathrm{km}^{-1}\right)$. A number of algorithms have been introduced in the literature for estimation of rainfall using radar measurements from a polarization diversity radar operating in the linear polarization basis. In this paper we focus on algorithms that have been used extensively in the literature. These algorithms can be broadly classified into three categories, namely, (i) algorithms that use reflectivity and differential reflectivity $R\left(Z_{h}, Z_{\mathrm{dr}}\right)$, (ii) algorithms that use differential propagation phase $R\left(K_{\mathrm{dp}}\right)$, and (iii) algorithms that use differential propagation phase and differential reflectivity $R\left(K_{\mathrm{dp}}, Z_{\mathrm{dr}}\right)$. These algorithms have the form

$$
R\left(Z_{h}, Z_{\mathrm{dr}}\right)=c_{1} Z_{H}^{a} 10^{-b_{1} Z_{\mathrm{dr}}}
$$

(Gorgucci et al. 1995),

$$
R\left(K_{\mathrm{dp}}\right)=c_{2} K_{\mathrm{dp}}^{a_{2}}
$$

(Sachidananda and Zrnić 1987; Chandrasekar et al. 1990), and

$$
R\left(K_{\mathrm{dp}}, Z_{\mathrm{dr}}\right)=c_{3} K_{\mathrm{dp}}^{a_{3}} 10^{-0.1 b_{3} Z_{\mathrm{dr}}}
$$

(Seliga and Bringi 1978; Jameson 1991; Ryzhkov and Zrnić 1995; Gorgucci and Scarchilli 1997).

\section{Bias in rainfall algorithms due to varying mean raindrop shape-size relation}

It can be seen from (5) that raindrops become more oblate with increasing size. Therefore, varying the shapesize relation should change the values of $Z_{\mathrm{dr}}$ and $K_{\mathrm{dp}}$ for a given RSD. Gorgucci et al. (2000a) demonstrated that $Z_{h}$ is fairly insensitive to varying $\beta$, whereas $Z_{\mathrm{dr}}$ and $K_{\mathrm{dp}}$ can vary significantly. Thus, the resulting rain-rate estimates will be biased if the actual shape-size relation is different from that assumed. The effect of varying the shape-size relation is illustrated by the following anal- ysis. For a given RSD, at S-band frequency of $2.8 \mathrm{GHz}$, $Z_{h}, Z_{\mathrm{dr}}$, and $K_{\mathrm{dp}}$ are calculated assuming $\beta=\beta_{e}=0.062$. A large table of $Z_{h}, Z_{\mathrm{dr}}$, and $K_{\mathrm{dp}}$ values is derived by varying the parameters characterizing the gamma RSD over a wide range, namely, $-1<\mu<5,3<\log N_{w}<$ 5 , and $0.5<D_{0}<2.5$. Nonlinear regression is then used to estimate the coefficients $(c, a, b)$ listed in (10)-(12); note that the "true" rain rate $R$ is obtained by integrating $v(D) D^{3} N(D)$ where $v(D)$ is the terminal velocity. Note that the variation of the RSD parameters automatically yields a distribution of $R$, which is typically large at low rain rates and small at high rain rates. Subsequently, $\beta$ is varied between 0.02 to 0.1 , the corresponding $Z_{h}, Z_{\mathrm{dr}}$, and $K_{\mathrm{dp}}$ are again calculated and, in turn, used in the algorithms listed in (10)-(12) whose coefficients are only valid for $\beta=\beta_{e}$. Figure 1 shows the biases of $R\left(Z_{h}, Z_{\mathrm{dr}}\right)$, $R\left(K_{\mathrm{dp}}\right)$, and $R\left(K_{\mathrm{dp}}, Z_{\mathrm{dr}}\right)$, normalized with respect to the respective estimates obtained at $\beta=\beta_{e}$. The following observations can be made from Fig. 1. Among the three algorithms, $R\left(K_{\mathrm{dp}}, Z_{\mathrm{dr}}\right)$ is the least sensitive to $\beta$, especially when $\beta>\beta_{e}\left(\beta_{e}=0.062\right)$. Here $R\left(Z_{h}, Z_{\mathrm{dr}}\right)$ and $R\left(K_{\mathrm{dp}}\right)$ are fairly sensitive to variation in $\beta$, resulting in significant biases. The bias in $R\left(Z_{h}, Z_{\mathrm{dr}}\right)$ and $R\left(K_{\mathrm{dp}}\right)$ are of opposite signs. In addition, the sign of the bias for $R\left(Z_{h}, Z_{\mathrm{dr}}\right)$ and $R\left(K_{\mathrm{dp}}\right)$ changes when $\beta$ goes from $\beta \leq$ $\beta_{e}$ to $\beta \geq \beta_{e}$. Thus, to avoid potentially large bias in rainfall estimates, it is important to develop algorithms that are immune to variability in raindrop shape-size relations.

\section{Development of polarimetric rainfall algorithm immune to variation in shape-size relation}

In order to develop rainfall algorithms that are independent of $\beta$, we need to evaluate the variation of the coefficients of algorithms listed in (10)-(12) for different values of $\beta$. Using simulations of the radar measurements as described in section 3 , and nonlinear regression analysis, the best coefficients of $R\left(Z_{h}, Z_{\mathrm{dr}}\right)$, $R\left(K_{\mathrm{dp}}\right)$, and $R\left(K_{\mathrm{dp}}, Z_{\mathrm{dr}}\right)$ are evaluated for different values of $\beta$ under a gamma RSD model. The coefficient set $\left(c_{1}, a_{1}, b_{1}\right),\left(c_{2}, a_{2}\right)$, and $\left(c_{3}, a_{3}, b_{3}\right)$ can change with $\beta$ as illustrated in Fig. 2. Figure 2a shows that the exponent $\left(a_{1}\right)$ of $Z_{h}$ is not very sensitive to $\beta$ but the coefficient $\left(b_{1}\right)$ multiplying $Z_{\mathrm{dr}}$ varies considerably. This is expected because variation of $\beta$ impacts $Z_{\mathrm{dr}}$ more than $Z_{h}$. In addition, the constant multiplier $\left(c_{1}\right)$ also varies significantly with $\beta$. Similarly, Fig. $2 \mathrm{~b}$ shows that the multiplication constant $\left(c_{2}\right)$ adjusts itself to account for varying $\beta$ (or, $K_{\mathrm{dp}}$ ), whereas $a_{2}$ does not vary significantly. Figure $2 \mathrm{c}$ shows the variation of $c_{3}, a_{3}$, and $b_{3}$ where all the three parameters vary with $\beta$. In summary, the prevailing $\beta$ has a significant influence on the choice of algorithm to estimate rainfall. Gorgucci et al. (2000a) have shown that polarimetric radar observations can be used to estimate $\hat{\beta}$ and the estimator for $\beta$, at $\mathrm{S}$ band (frequency of $2.8 \mathrm{GHz}$ ), is given by 

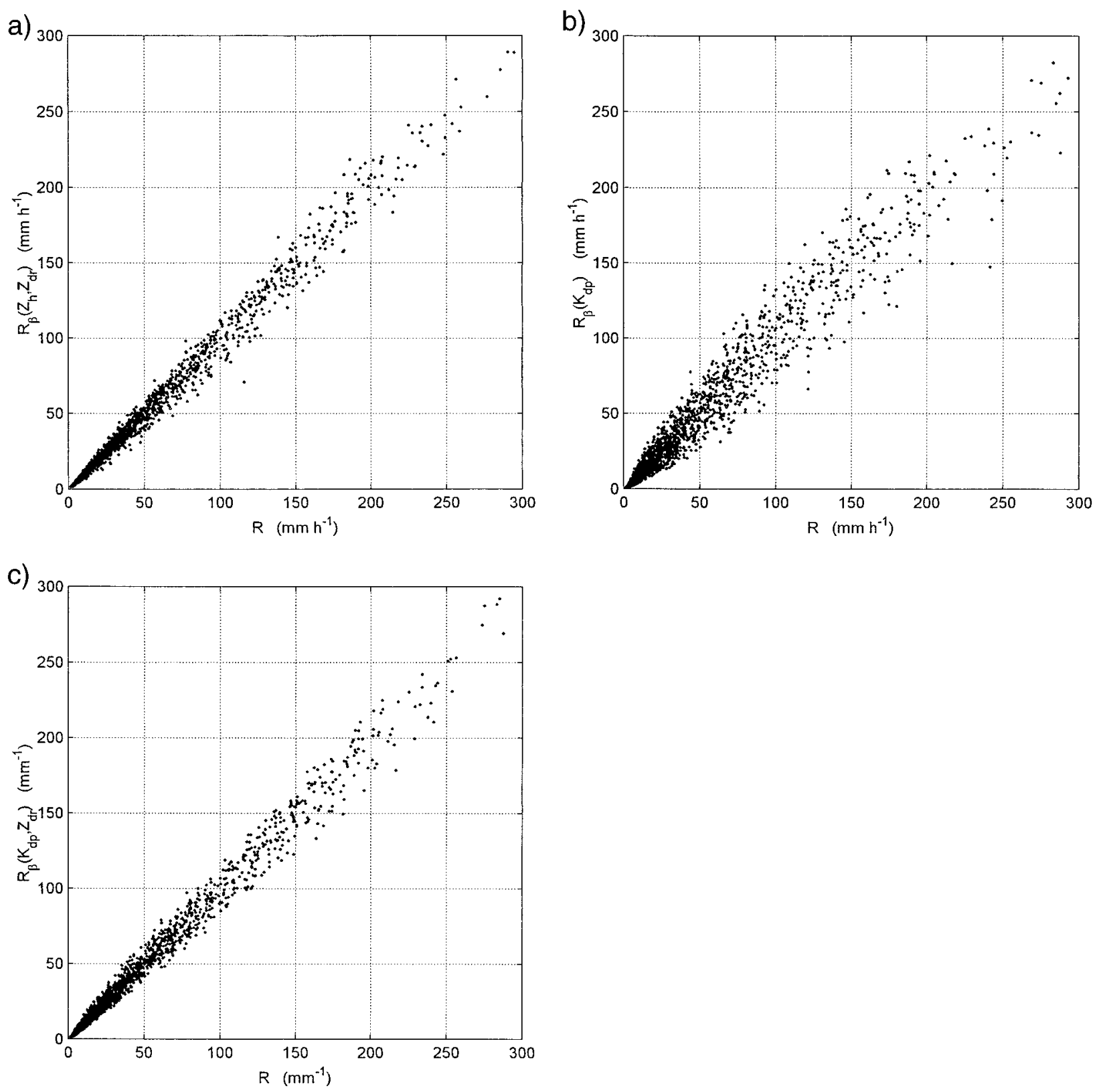

FIG. 3. (a) Scattergram of $R_{\beta}\left(Z_{h}, Z_{\mathrm{dr}}\right)$ algorithm vs $R$. (b) Scattergram of $R_{\beta}\left(K_{\mathrm{dp}}\right)$ algorithm vs $R$. (c) Scattergram of $R_{\beta}\left(K_{\mathrm{dp}}, Z_{\mathrm{dr}}\right)$ algorithm vs $R$.

$$
\hat{\beta}=2.08 \times Z_{h}^{-0.365} 10^{0.0965} Z_{\mathrm{dr}} K_{\mathrm{dp}}^{0.380} .
$$

Note that the above parameterization (13) is slightly different from the equation given in Gorgucci et al. (2000a), but yields similar results. Therefore, in principle if $\beta$ can be estimated then an appropriate algorithm can be obtained from Fig. 2. However, in practice this can get cumbersome. It is easier if the variability due to $\beta$ can be built into the algorithms. The following set of parametric forms is derived incorporating $\beta$ into the radar rainfall algorithms as

$$
R_{\beta}\left(Z_{h}, Z_{\mathrm{dr}}\right)=c_{1} Z_{h}^{a_{1}} 10^{-0.1 b_{1} Z_{\mathrm{dr}}}
$$

where

$$
\begin{aligned}
& c_{1}=0.105 \beta^{0.865}, \\
& a_{1}=0.93 \\
& b_{1}=-0.585 \beta^{-0.703} .
\end{aligned}
$$

Similarly, 


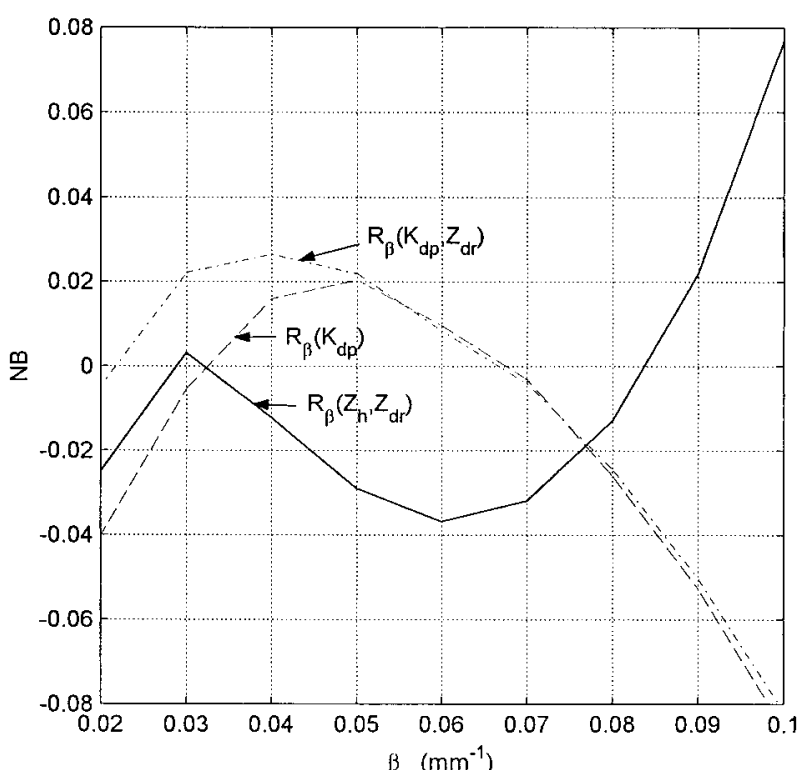

FIG. 4. The NB of $R_{\beta}\left(Z_{h}, Z_{\mathrm{dr}}\right), R_{\beta}\left(K_{\mathrm{dp}}\right)$, and $R_{\beta}\left(K_{\mathrm{dp}}, Z_{\mathrm{dr}}\right)$ algorithms as a function of $\beta$. Note that the bias is negligible in comparison to the results of Fig. 1.

$$
R_{\beta}\left(K_{\mathrm{dp}}\right)=c_{2} K_{\mathrm{dp}}^{a_{2}}
$$

where

$$
\begin{aligned}
c_{2} & =0.440 \beta^{-1.612}, \\
a_{2} & =1.596 \beta^{0.175}, \text { and } \\
R_{\beta}\left(K_{\mathrm{dp}}, Z_{\mathrm{dr}}\right) & =c_{3} K_{\mathrm{dp}}^{a_{3}} 10^{-0.1 b_{3} Z_{\mathrm{dr}}},
\end{aligned}
$$

where

$$
\begin{aligned}
& c_{3}=0.481 \beta^{-1.795}, \\
& a_{3}=1.337 \beta^{0.117}, \text { and } \\
& b_{3}=-0.014 \beta^{-1.674} .
\end{aligned}
$$

Thus, the above algorithms (14), (16), and (18) can be used to estimate rainfall rate for arbitrary $\beta$, which can be estimated by (13). It can be shown that the final equations of the rainfall rate estimates exhibit a more complicated power-law dependence.

\section{Performance of the parameterization}

The performance of the above three algorithms $R_{\beta}\left(Z_{h}\right.$, $\left.Z_{\mathrm{dr}}\right), R_{\beta}\left(K_{\mathrm{dp}}\right)$, and $R_{\beta}\left(K_{\mathrm{dp}}, Z_{\mathrm{dr}}\right)$ is evaluated in this section based on gamma RSD simulations. Figure 3a shows a scatterplot of $R_{\beta}\left(Z_{h}, Z_{\mathrm{dr}}\right)$ versus $R$ for various RSD, described in section 3 , and $\beta$ varying between 0.02 to 0.1 . It can be seen from Fig. 3 a that $R_{\beta}\left(Z_{h}, Z_{\mathrm{dr}}\right)$ estimates $R$ fairly well for all $\beta$ in the assumed range. Similarly, Fig. 3b shows the scatterplot of $R_{\beta}\left(K_{\mathrm{dp}}\right)$ versus $R$ whereas Fig. 3c shows the scatterplot of $R_{\beta}\left(K_{\mathrm{dp}}, Z_{\mathrm{dr}}\right)$ versus

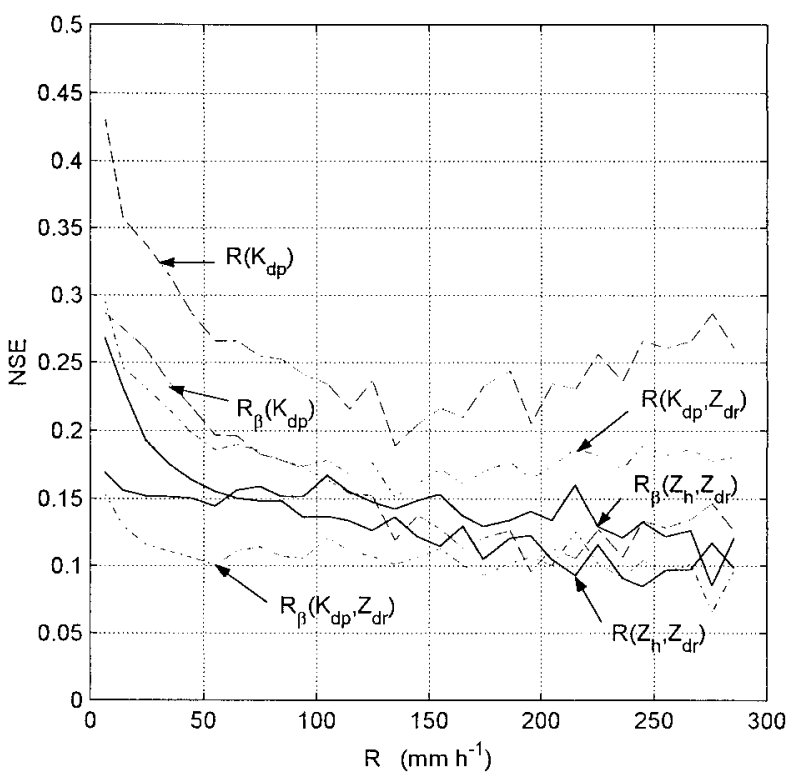

FIG. 5. Normalized standard error (NSE) of $R\left(Z_{h}, Z_{\mathrm{dr}}\right), R\left(K_{\mathrm{dp}}\right)$, $R\left(K_{\mathrm{dp}}, Z_{\mathrm{dr}}\right), R_{\beta}\left(Z_{h}, Z_{\mathrm{dr}}\right), R_{\beta}\left(K_{\mathrm{dp}}\right)$, and $R_{\beta}\left(K_{\mathrm{dp}}, Z_{\mathrm{dr}}\right)$ algorithms as a function of $R$, when the prevailing shape-size relation is the BC model. Note that in general $R_{\beta}$ algorithms have less NSE.

$R$. Figures $3 \mathrm{~b}$ and $3 \mathrm{c}$ show that $R_{\beta}\left(K_{\mathrm{dp}}, Z_{\mathrm{dr}}\right)$ performs better than $R_{\beta}\left(K_{\mathrm{dp}}\right)$ for estimating $R$, for arbitrary $\beta$. Quantitative analysis of these simulation results yielded a normalized standard error (NSE) of about $11.9 \%$ for $R_{\beta}\left(Z_{h}, Z_{\mathrm{dr}}\right), 25.1 \%$ for $R_{\beta}\left(K_{\mathrm{dp}}\right)$, and $12.4 \%$ for $R_{\beta}\left(K_{\mathrm{dp}}\right.$, $Z_{\mathrm{dr}}$ ), where NSE is defined as

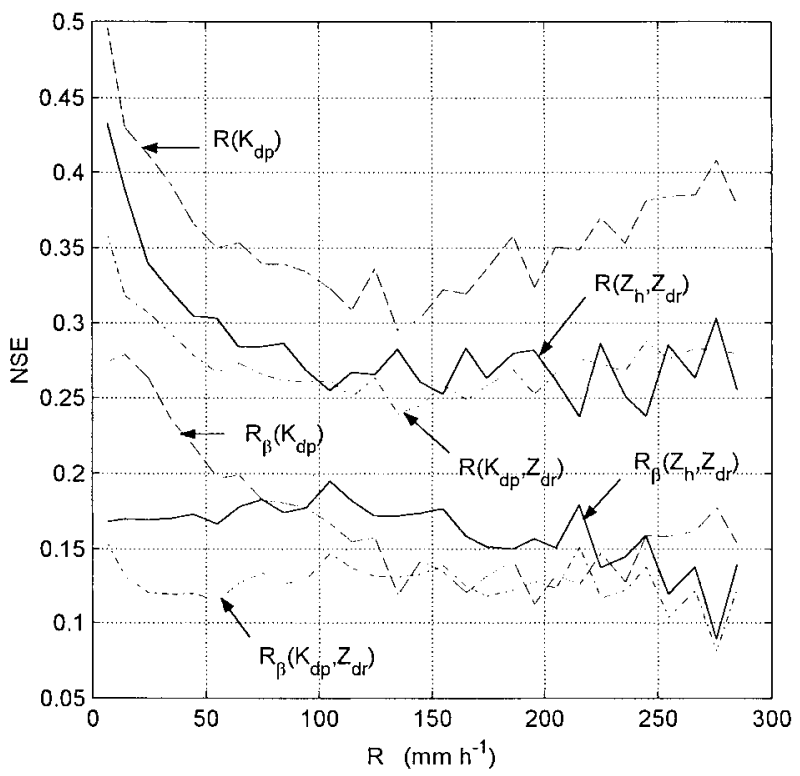

FIG. 6. NSE of $R\left(Z_{h}, Z_{\mathrm{dr}}\right), R\left(K_{\mathrm{dp}}\right), R\left(K_{\mathrm{dp}}, Z_{\mathrm{dr}}\right), R_{\beta}\left(Z_{h}, Z_{\mathrm{dr}}\right), R_{\beta}\left(K_{\mathrm{dp}}\right)$, and $R_{\beta}\left(K_{\mathrm{dp}}, Z_{\mathrm{dr}}\right)$ algorithms as a function of $R$, when the prevailing shape-size relation is the ABL model. Note that $R_{\beta}$ algorithms have substantially lower NSE. 

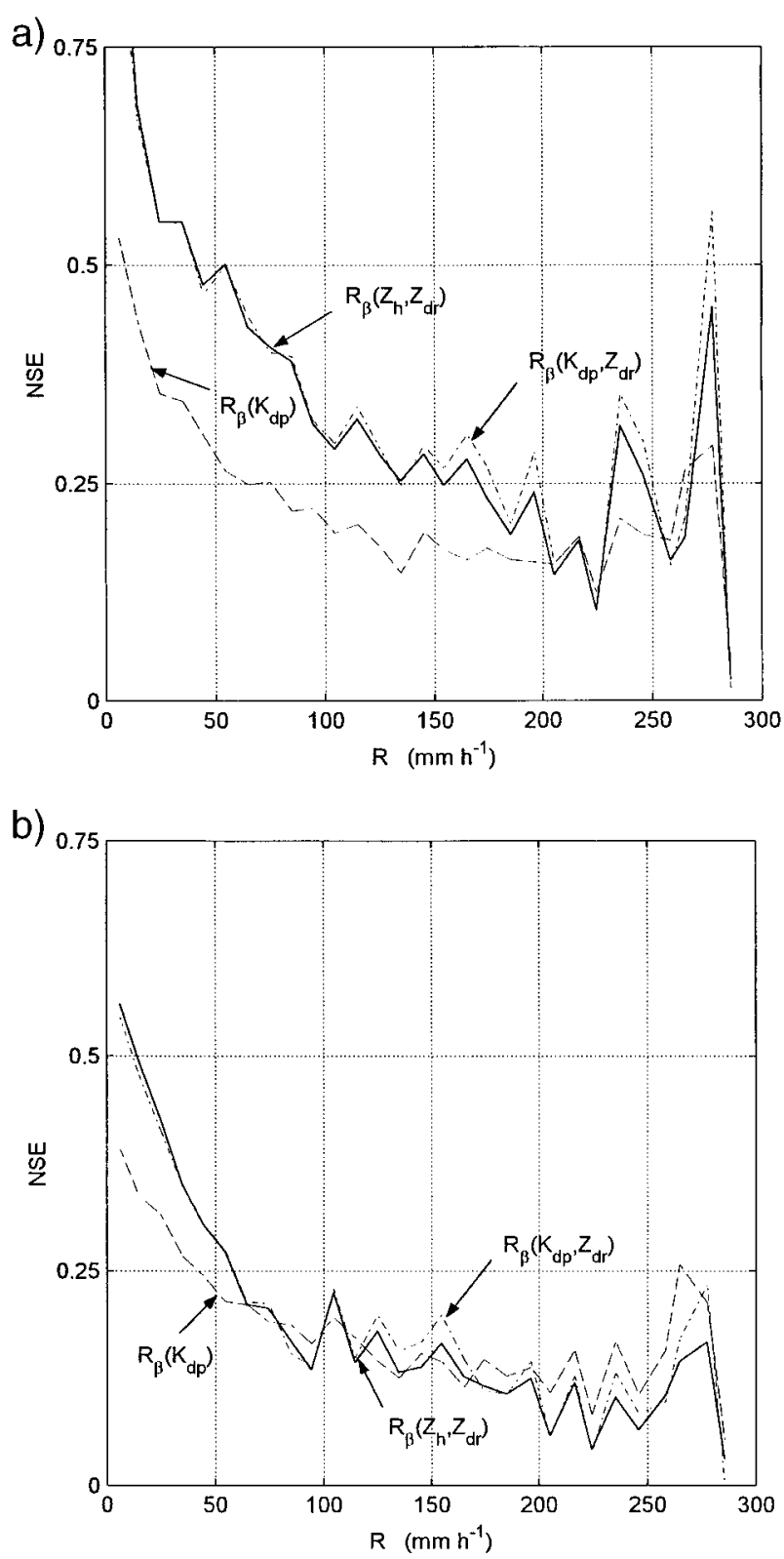

FIG. 7. (a) NSE of $R_{\beta}\left(Z_{h}, Z_{\mathrm{dr}}\right), R_{\beta}\left(K_{\mathrm{dp}}\right)$, and $R_{\beta}\left(K_{\mathrm{dp}}, Z_{\mathrm{dr}}\right)$ algorithms in the presence of measurement error, when estimated over a $3-\mathrm{km}$ path, given as a function of $R$. (b) NSE of $R_{\beta}\left(Z_{h}, Z_{\mathrm{dr}}\right), R_{\beta}\left(K_{\mathrm{dp}}\right)$, and $R_{\beta}\left(K_{\mathrm{dp}}, Z_{\mathrm{dr}}\right)$ algorithms in the presence of measurement error, when estimated over a $6-\mathrm{km}$ path, given as a function of $R$.

$$
\mathrm{NSE}=\frac{\left[\left\langle\left(\hat{R}_{\beta}-R\right)^{2}\right\rangle\right]^{1 / 2}}{\langle R\rangle},
$$

where $\hat{R}_{\beta}$ indicates one of the estimators defined in (14), (16), or (18), the angle brackets indicate averaged value and $R$ is the true rain rate.

The main objective of deriving $R_{\beta}$ is to eliminate the bias error in rainfall estimates due to different shapesize relations. To demonstrate this, the bias in $R_{\beta}$ is computed for different $\beta$ by varying the RSD over a wide range as described in section 3 . The normalized bias in the various algorithms is computed as a function of $\beta$. Normalized bias (NB) is defined as

$$
\mathrm{NB}=\frac{\left\langle\hat{R}_{\beta}-R\right\rangle}{\langle R\rangle} .
$$

Figure 4 shows the normalized bias for $R_{\beta}\left(Z_{h}, Z_{\mathrm{dr}}\right)$, $R_{\beta}\left(K_{\mathrm{dp}}\right)$, and $R_{\beta}\left(K_{\mathrm{dp}}, Z_{\mathrm{dr}}\right)$ as a function of $\beta$. It can be seen from Fig. 4 that the bias due to variation in $\beta$ is negligible compared to that shown in Fig. 1.

The model presented in this paper makes a linear approximation to the shape-size relationship. However, as pointed out earlier in the introduction some commonly used models for shape-size relations are nonlinear. The following analysis evaluates the performance of $R_{\beta}$ algorithms under this context. $Z_{h}, Z_{\mathrm{dr}}$, and $K_{\mathrm{dp}}$ values are simulated for widely varying RSD, assuming that the raindrop shape follows the $\mathrm{BC}$ and $\mathrm{ABL}$ models. Subsequently, $R_{\beta}$ algorithms described by (14), (16), and (18) are applied to the simulated observables $Z_{h}$, $Z_{\mathrm{dr}}$, and $K_{\mathrm{dp}}$. Figures 5 and 6 show NSE of rainfall estimates for two nonlinear shape-size models, namely, the $\mathrm{BC}$ and $\mathrm{ABL}$ models, respectively, as a function of rain rate. Figure 5 shows the NSE in $R\left(Z_{h}, Z_{\mathrm{dr}}\right), R\left(K_{\mathrm{dp}}\right)$, and $R\left(K_{\mathrm{dp}}, Z_{\mathrm{dr}}\right)$ based on the PB model as well as $R_{\beta}\left(Z_{h}\right.$, $\left.Z_{\mathrm{dr}}\right), R_{\beta}\left(K_{\mathrm{dp}}\right)$, and $R_{\beta}\left(K_{\mathrm{dp}}, Z_{\mathrm{dr}}\right)$. It can be seen from Fig. 5 that all the three polarimetric algorithms based on the BC model have higher NSE, whereas the algorithms derived in this paper have lower NSE. This feature is clear for $R\left(K_{\mathrm{dp}}\right)$ and $R\left(K_{\mathrm{dp}}, Z_{\mathrm{dr}}\right)$, whereas for $R\left(Z_{h}, Z_{\mathrm{dr}}\right)$ the improvement is significant only up to moderate rain rates $\left(R<60 \mathrm{~mm} \mathrm{~h}^{-1}\right)$. This result is even more pronounced when the ABL model is used. Figure 6 shows the NSE in $R\left(Z_{h}, Z_{\mathrm{dr}}\right), R\left(K_{\mathrm{dp}}\right)$, and $R\left(K_{\mathrm{dp}}, Z_{\mathrm{dr}}\right)$ as well as $R_{\beta}\left(Z_{h}, Z_{\mathrm{dr}}\right), R_{\beta}\left(K_{\mathrm{dp}}\right)$, and $R_{\beta}\left(K_{\mathrm{dp}}, Z_{\mathrm{dr}}\right)$, where all estimates based on the ABL model have uniformly higher NSE than the algorithms based on (14), (16), and (18). Thus, in summary, the composite algorithms developed in this paper and the simulation results show that rain rate can be accurately estimated, without having to assume a specific shape-size relation such as the equilibrium mode.

\section{Error structure and sensitivity of the rainfall algorithms}

The performance of the algorithms $R_{\beta}\left(Z_{h}, Z_{\mathrm{dr}}\right)$, $R_{\beta}\left(K_{\mathrm{dp}}\right)$, and $R_{\beta}\left(K_{\mathrm{dp}}, Z_{\mathrm{dr}}\right)$ depend on the parameterization as well as measurement errors. There are two types of measurement errors, namely, random measurement errors and systematic bias errors. The nature of the algorithms $R_{\beta}\left(Z_{h}, Z_{\mathrm{dr}}\right), R_{\beta}\left(K_{\mathrm{dp}}\right)$, and $R_{\beta}\left(K_{\mathrm{dp}}, Z_{\mathrm{dr}}\right)$ involves estimation of $\beta$ first, and therefore any error in any of the three measurements, namely, $Z_{h}, Z_{\mathrm{dr}}$, and $K_{\mathrm{dp}}$ will affect all the three estimators.

Here $Z_{h}$ is based on absolute power measurement and has a typical accuracy of $1 \mathrm{~dB}$. The $Z_{\mathrm{dr}}$ is a relative 
a)

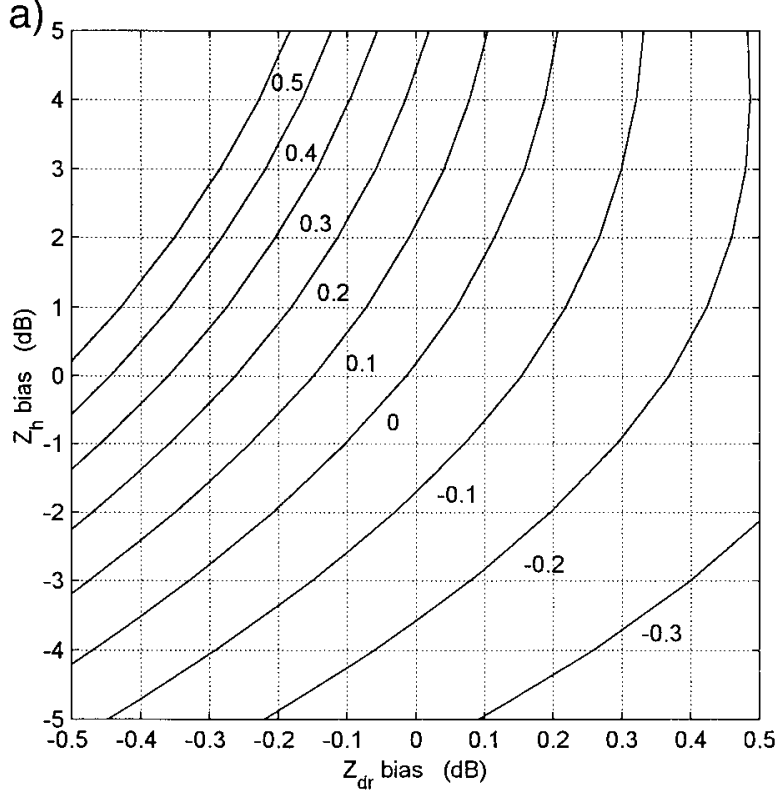

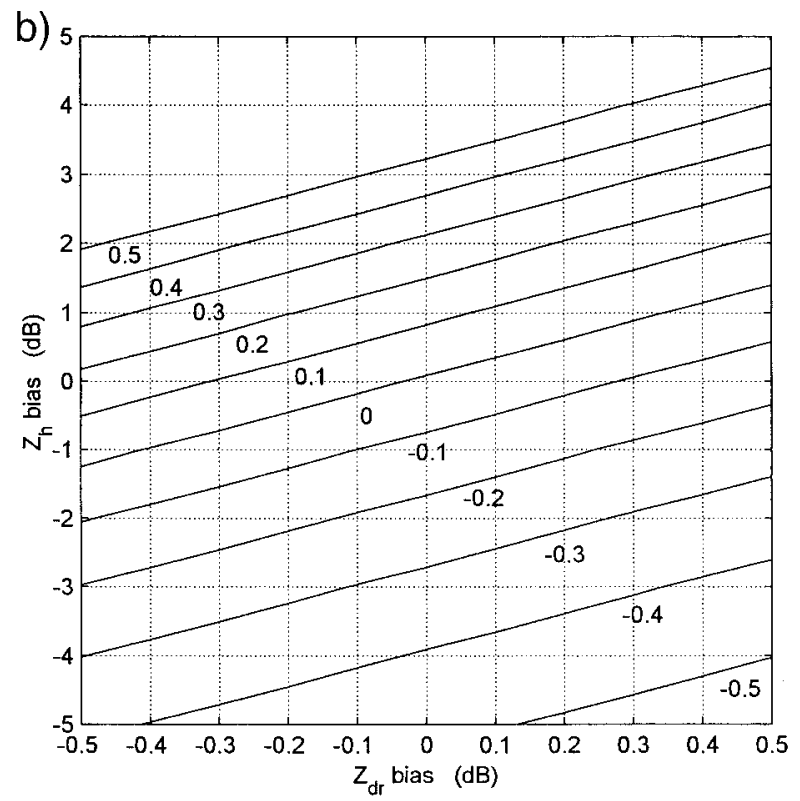

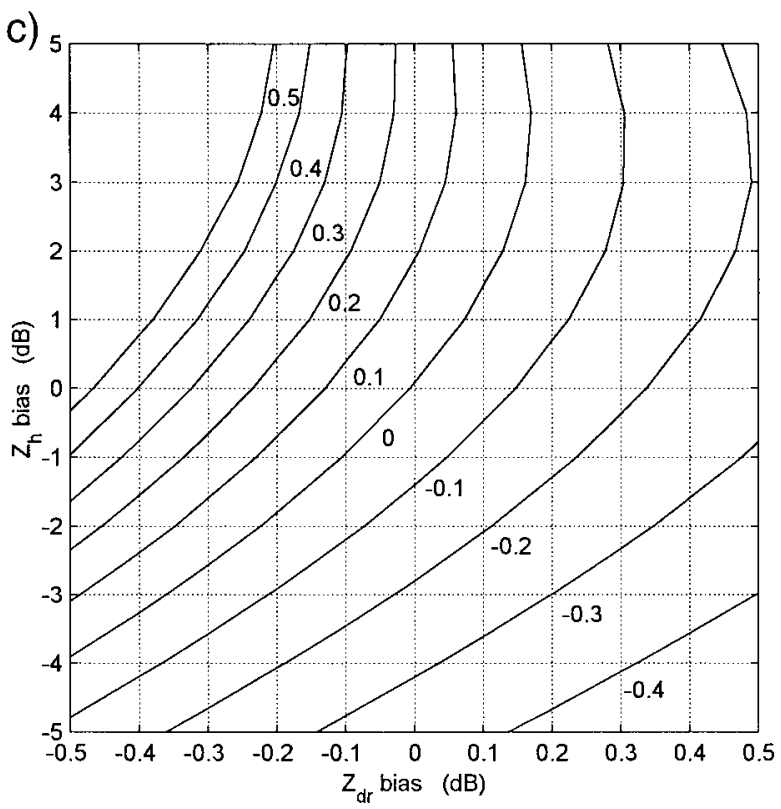

FIG. 8. (a) Contour plot of NB in $R_{\beta}\left(Z_{b}, Z_{\mathrm{d}}\right)$ due to bias in $Z_{b}$ and $Z_{\mathrm{d} .}$. (b) Contour plot of NB in $R_{\beta}\left(K_{\mathrm{dp}}\right)$ due to bias in $Z_{b}$ and $Z_{\mathrm{d} d}$. Note that $R_{\beta}\left(K_{\mathrm{dp}}\right)$ is affected by bias in $Z_{h}$ and $Z_{\mathrm{dr}}$ through the estimation of $\beta$. (c) Contour plot of NB in $R_{\beta}\left(K_{\mathrm{dp}}, Z_{\mathrm{dr}}\right)$ due to bias in $Z_{h}$ and $Z_{\mathrm{dr}}$. Though the algorithm explicitly does not use $Z_{h}$, the algorithm is affected through the estimation of $\beta$.

power measurement. It can be estimated to an accuracy of $0.2 \mathrm{~dB}$. Here $K_{\mathrm{dp}}$ is the slope of the range profile of differential propagation phase $\Phi_{\mathrm{dp}}$, which can be estimated to an accuracy of $2^{\circ}-3^{\circ}$. The subsequent estimate of $K_{\mathrm{dp}}$ depends on the type of procedure used, such as, a simple finite-difference scheme or a least squares fit. Using a least squares estimate of the $\Phi_{\mathrm{dp}}$ range profile the standard deviation of $K_{\mathrm{dp}}$ can be expressed as (Gorgucci et al. 2000b)

$$
\sigma\left(K_{\mathrm{dp}}\right)=\sqrt{3} \frac{\sigma\left(\Phi_{\mathrm{dp}}\right)}{N \Delta r} \sqrt{\frac{N}{(N-1)(N+1)}},
$$

where $\Delta r$ is the range resolution of the $\Phi_{\mathrm{dp}}$ estimate and $N$ is the number of range samples within the path. For large $N$ we can see that $\sigma\left(K_{\mathrm{dp}}\right)$ decreases as $N^{3 / 2}$. For a typical $150 \mathrm{~m}$ range spacing, and $\Phi_{\mathrm{dp}}$ accuracy of $2.5^{\circ}$, $K_{\text {dp }}$ can be estimated, over a path of $2.1 \mathrm{~km}$, with a standard error of $0.55^{\circ} \mathrm{km}^{-1}$. Thus, the three measure- 


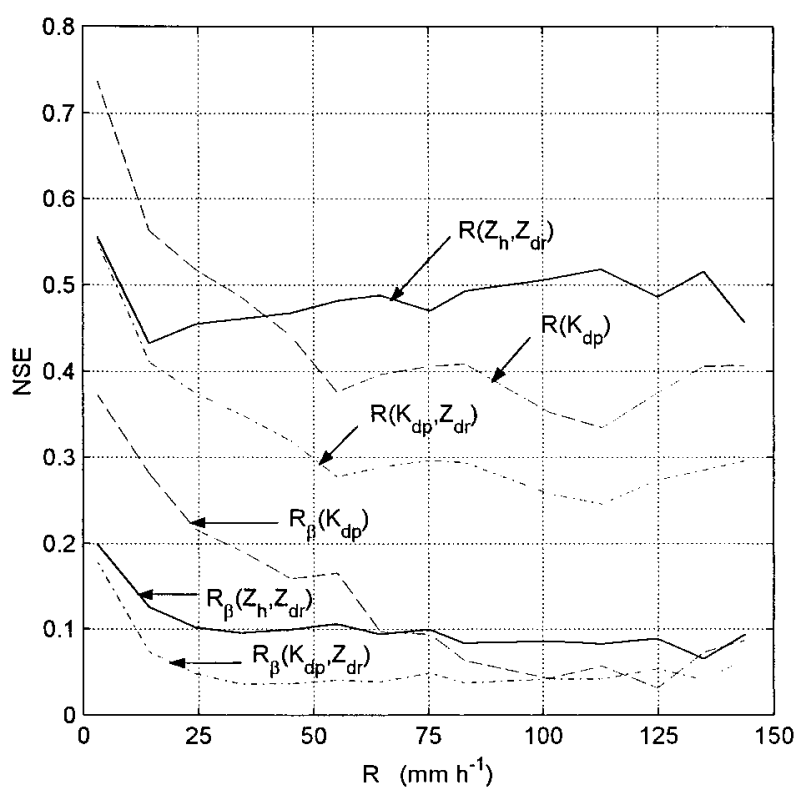

FIG. 9. NSE of $R\left(Z_{h}, Z_{\mathrm{dr}}\right), R\left(K_{\mathrm{dp}}\right), R\left(K_{\mathrm{dp}}, Z_{\mathrm{dr}}\right), R_{\beta}\left(Z_{h}, Z_{\mathrm{dr}}\right), R_{\beta}\left(K_{\mathrm{dp}}\right)$, and $R_{\beta}\left(K_{\mathrm{dp}}, Z_{\mathrm{dr}}\right)$ algorithms computed from disdrometer simulations. The axis ratio model used for simulation is the ABL model. Note that $R_{\beta}$ algorithms have significantly smaller NSE.

ments $Z_{h}, Z_{\mathrm{dr}}$, and $K_{\mathrm{dp}}$ have completely different error structure, and in addition, the measurement errors of $Z_{h}$, $Z_{\mathrm{dr}}$, and $K_{\mathrm{dp}}$ are nearly independent. Therefore, the three measurements, when used in rainfall algorithms, result in very different error structure of rainfall estimates. In the following we use simulations to evaluate the error structure of rainfall algorithms described by (14), (16), and (18). The simulation is done as follows. Various rain-rate values are simulated by varying the parameters of the gamma RSD over a wide range as described in section 3. For each RSD, the corresponding $Z_{h}, Z_{\mathrm{dr}}$, and $K_{\mathrm{dp}}$ are evaluated using (7)-(9) choosing a random value of $\beta$ between 0.02 and 0.1 . Random measurement errors are simulated using the procedure described in Chandrasekar et al. (1986). The principal parameters of our simulation are as follows: (i) wavelength $\lambda=10.7 \mathrm{~cm}$, (ii) sampling time PRT $=1 \mathrm{~ms}$, (iii) number of sample pairs $M=64$, (iv) Doppler velocity spectrum width $\sigma_{v}$ $=2 \mathrm{~m} \mathrm{~s}^{-1}$, (v) copolar correlation between $H$ and $V$ signals $\rho_{\mathrm{h} v}=0.99$, and (vi) $K_{\mathrm{dp}}$ is estimated as the slope of the line obtained from a least squares fit to the $\Phi_{\mathrm{dp}}$ profile, with samples spaced $150 \mathrm{~m}$.

The following analysis compares the performance of the polarimetric radar rainfall algorithms under ideal conditions of uniform rainfall over the path where $K_{\mathrm{dp}}$ is estimated. Simulations were performed for uniform rainfall path over 20 and 40 range bins corresponding to 3- and 6-km path, respectively, in the presence of measurement errors. Figures $7 \mathrm{a}$ and $7 \mathrm{~b}$ show the normalized standard error of $R_{\beta}\left(Z_{h}, Z_{\mathrm{dr}}\right), R_{\beta}\left(K_{\mathrm{dp}}\right)$, and $R_{\beta}\left(K_{\mathrm{dp}}, Z_{\mathrm{dr}}\right)$ as a function of $R$ for 3 - and $6-\mathrm{km}$ path, respectively. It can be seen from Fig. 7 that on the average, the error in rain-rate estimate due to measurement errors and parameterization in the algorithm is of the order of $35 \%$ for $3-\mathrm{km}$ path and $25 \%$ for $6-\mathrm{km}$ path. A comparison between Figs. $7 \mathrm{a}$ and $7 \mathrm{~b}$ show that the errors are less when the rain rate is estimated over a 6$\mathrm{km}$ path in comparison to a $3-\mathrm{km}$ path. In addition to radar measurement errors, systematic bias errors can be present in $Z_{h}$ and $Z_{\mathrm{dr}}$. In a well-maintained radar system, bias error in $Z_{h}$ and $Z_{\mathrm{dr}}$ should be less than 1 and 0.15 $\mathrm{dB}$, respectively. Figures $8 \mathrm{a}-\mathrm{c}$ show the contours of mean normalized standard errors for $R_{\beta}\left(Z_{h}, Z_{\mathrm{dr}}\right)$, $R_{\beta}\left(K_{\mathrm{dp}}\right)$, and $R_{\beta}\left(K_{\mathrm{dp}}, Z_{\mathrm{dr}}\right)$, respectively, as a function of bias errors in $Z_{h}$ and $Z_{\mathrm{dr}}$. It can be observed from Fig. 8 that for biases in $Z_{h}<1 \mathrm{~dB}$ and $Z_{\mathrm{dr}}<0.15 \mathrm{~dB}$, the performance of the algorithms does not deteriorate significantly. Note that in Fig. 8b even though the algorithm is based on $K_{\mathrm{dp}}$, the coefficient depends on $Z_{h}$ and $Z_{\mathrm{dr}}$. Therefore, bias errors in $Z_{h}$ and $Z_{\mathrm{dr}}$ will deteriorate the performance of $R_{\beta}\left(K_{\mathrm{dp}}\right)$. The contour lines in the error for all three algorithms are denser when the bias in $Z_{h}$ is negative and $Z_{\mathrm{dr}}$ is positive, indicating that a combination of negative bias in $Z_{h}$ and positive bias in $Z_{\mathrm{dr}}$ is more detrimental to the algorithm than other combinations. Bias errors in $Z_{h}$ and $Z_{\mathrm{dr}}$ with the same sign tend to cancel the influence of each other, and do not affect the performance significantly. Among the three, $R_{\beta}\left(K_{\mathrm{dp}}, Z_{\mathrm{dr}}\right)$ performs the best.

\section{Data analysis}

\section{a. Disdrometer analysis}

The composite rainfall algorithms developed in this paper are applied to Joss and Waldvogel (1967) disdrometer data collected during a rainfall season (covering about three months) from Darwin (Australia). The dataset was collected by the BRMC. The dataset included different rainfall types, with rain rates between 0 and $150 \mathrm{~mm} \mathrm{~h}^{-1}$. More than 20001 -min RSD samples were available; the mean rain rate was $10 \mathrm{~mm} \mathrm{~h}^{-1}$. For each 1 -min RSD sample, the $Z_{h}, Z_{\mathrm{dr}}$, and $K_{\mathrm{dp}}$ were computed assuming ABL axis ratio model, with a Gaussian canting angle distribution with mean zero and standard deviation of $10^{\circ}$. The simulated values of $Z_{h}, Z_{\mathrm{dr}}$, and $K_{\mathrm{dp}}$ were used in the composite rainfall algorithms $\left(R_{\beta}\right)$ given by (14), (16), and (18) for comparison against rain rate derived from the disdrometer data. The performance of the algorithms was characterized in terms of NSE given by (20). The NSE of rainfall estimates derived under the PB model were also computed. Figure 9 compares the NSE of the six algorithms, namely, $R\left(Z_{h}, Z_{\mathrm{dr}}\right)$, $R\left(K_{\mathrm{dp}}\right)$, and $R\left(K_{\mathrm{dp}}, Z_{\mathrm{dr}}\right)$ derived under the PB axis ratio model, as well as $R_{\beta}\left(Z_{h}, Z_{\mathrm{dr}}\right), R_{\beta}\left(K_{\mathrm{dp}}\right)$, and $R_{\beta}\left(K_{\mathrm{dp}}, Z_{\mathrm{dr}}\right)$. The NSE is presented as a function of rain rate. Figure 9 shows that all algorithms using PB model have large errors (of the order of 30\%-50\%). This is an expected result, because the prevailing model is ABL. However, by applying the algorithms (14), (16), and (18) devel- 

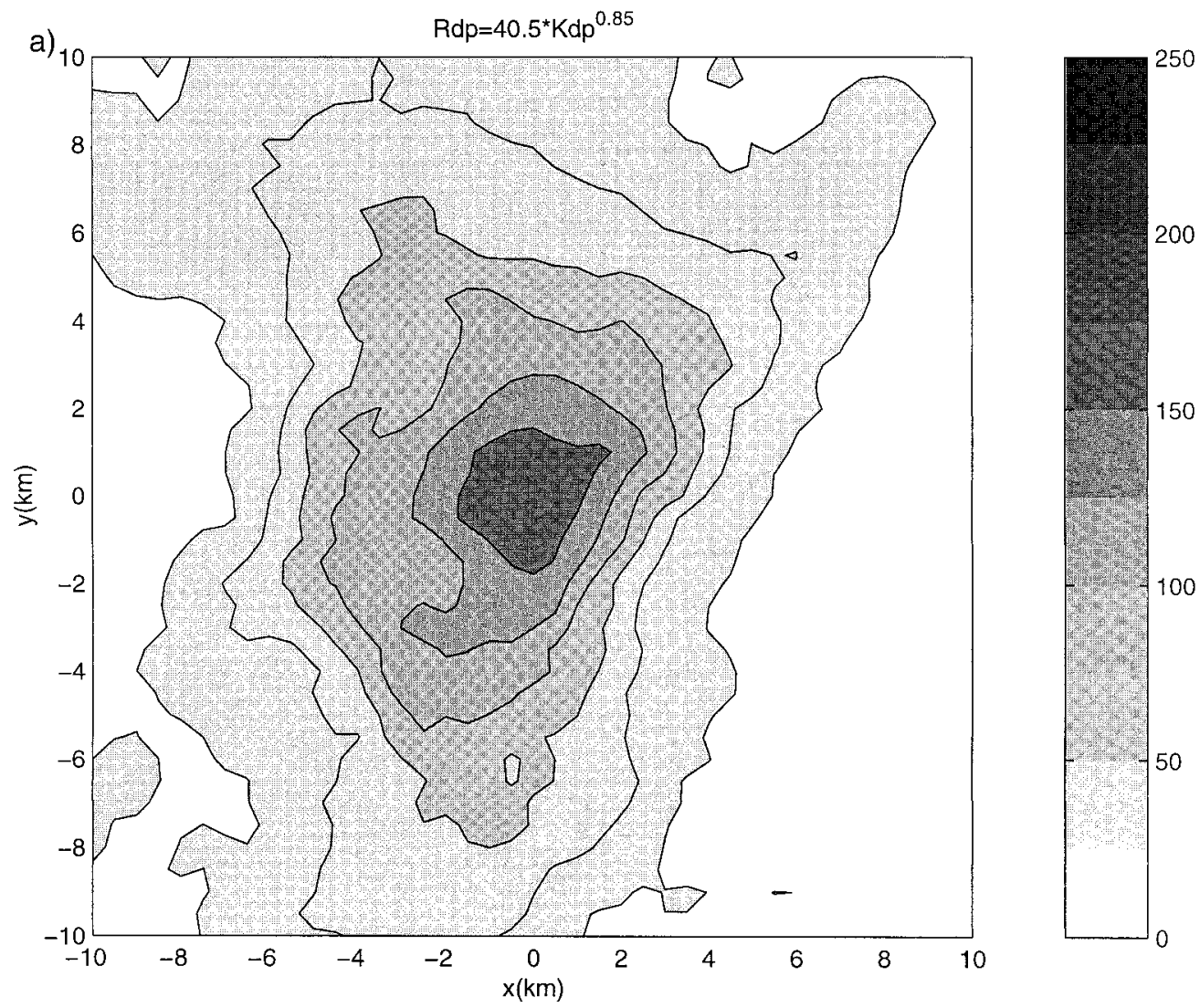

b) $\mathrm{Rdp}=\mathrm{C} 2^{*} \mathrm{Kdp} \mathrm{p}^{\mathrm{A} 2}$
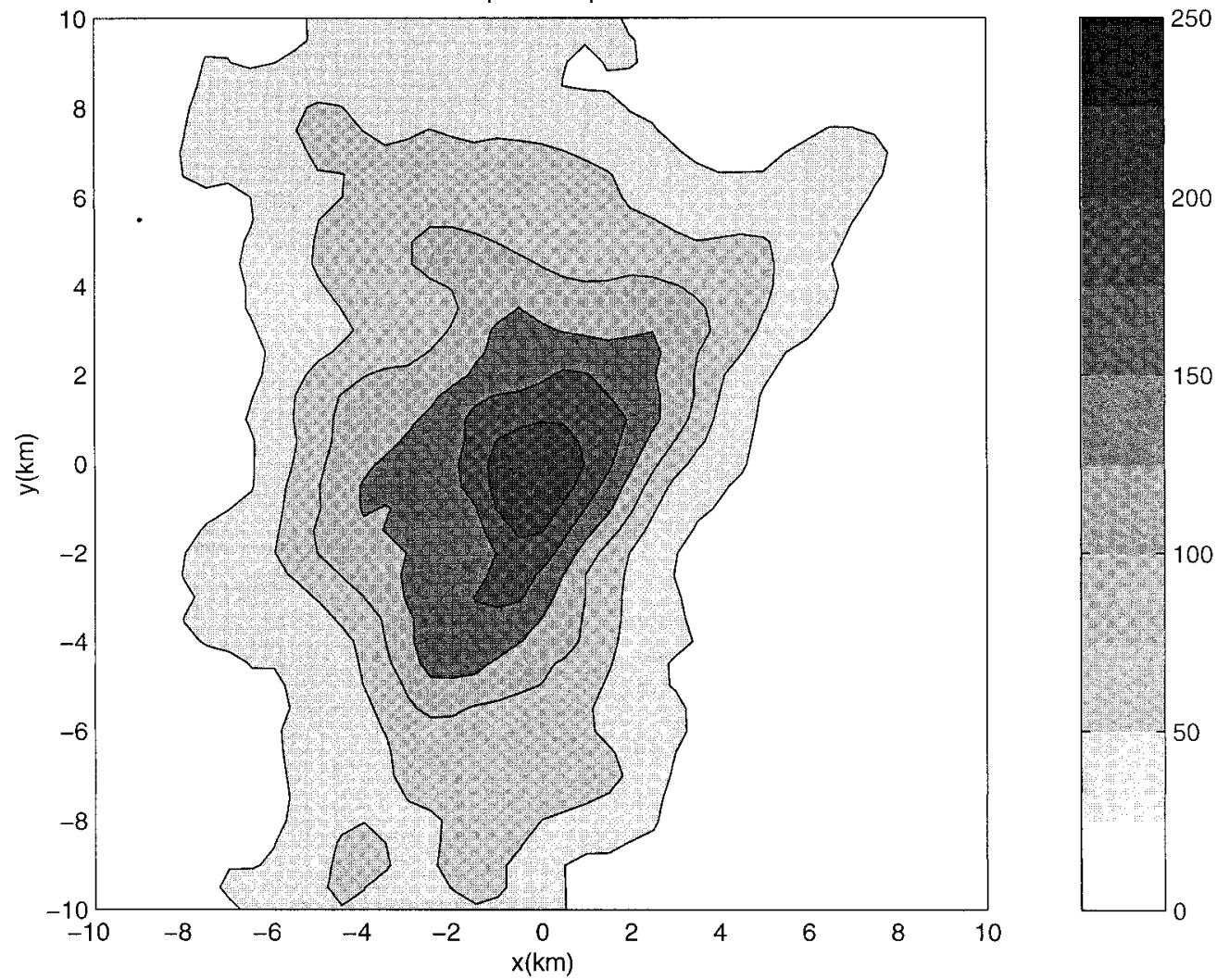
oped in this paper, the normalized standard errors are fairly small in agreement with the theoretical results. Among the three algorithms $R_{\beta}\left(K_{\mathrm{dp}}, Z_{\mathrm{dr}}\right)$ performs the best based on the disdrometer analysis.

\section{b. Radar-rain gauge comparison}

On the evening of 28 July 1997, the city of Fort Collins (Colorado) was hit by a flash flood, that caused fatalities and extensive property damage. Mesoscale analysis of this flood is described in Petersen et al. (1999). During this event the Colorado Climate Center documented rain gauge observations over Fort Collins. Petersen et al. (1999) computed storm total precipitation (STP) for this event, which was compared against corresponding observations from rain gauges. They concluded that the $R\left(K_{\mathrm{dp}}\right)$ algorithm based on the PB model $\left[40.5\left(K_{\mathrm{dp}}\right)^{0.85}\right]$ significantly underestimated the storm total precipitation. They also reported that the storm vertical structure was similar to that of tropical monsoonoceanic convection with warm rain (collision-coalescence) processes playing an important role in rainfall production. Conditions may have been suitable for raindrop oscillations, which tends to reduce $\beta$ from its equilibrium value. The commonly used $R\left(K_{\mathrm{dp}}\right)$ algorithm based on the PB model, and the composite algorithms developed in this paper were applied to the 28 July 1997 flood case for rainfall estimation. Radar measurements of $Z_{h}, Z_{\mathrm{dr}}$, and $K_{\mathrm{dp}}$ from the CSU-CHILL radar were interpolated to a Cartesian grid with horizontal and vertical resolution of $0.5 \mathrm{~km}$. Whenever $Z_{h}$ was more than $38 \mathrm{dBZ}$ at any grid point on the $z=1.0-\mathrm{km}$ plane, the composite rainfall algorithms based on (14), (16), and (18) were applied; for $Z_{h}<38 \mathrm{dBZ}$, a simple $Z-R$ relation was used ( $Z=140 R^{1.4}$; Petersen et al. 1999). Figure 10a shows contours of STP obtained from the $R\left(K_{\mathrm{dp}}\right)$ algorithm using the $\mathrm{PB}$ model, whereas Figs. $10 \mathrm{~b}, 11$, and 12 show contours of STP obtained from $R_{\beta}\left(K_{\mathrm{dp}}\right), R_{\beta}\left(Z_{h}, Z_{\mathrm{dr}}\right)$, and $R_{\beta}\left(K_{\mathrm{dp}}, Z_{\mathrm{dr}}\right)$. The peak STP obtained from rain gauges for this event was $260 \mathrm{~mm}$ (Petersen et al. 1999). First, the $R\left(K_{\mathrm{dp}}\right)$ algorithm using the PB model significantly underestimated the peak STP (156 mm vs gauge peak of $260 \mathrm{~mm}$ ). The application of the composite algorithm $R_{\beta}\left(K_{\mathrm{dp}}\right)$ as well as $R_{\beta}\left(Z_{h}\right.$, $\left.Z_{\mathrm{dr}}\right)$ or $R_{\beta}\left(K_{\mathrm{dp}}, Z_{\mathrm{dr}}\right)$ improved the peak STP estimates significantly $(220-230 \mathrm{~mm})$, but still slightly less than the peak gauge estimates. One possible explanation could be the time resolution of the radar data, which was about $15 \mathrm{~min}$. A simple analysis of the time records of one of the rain gauges indicated a $15 \%$ underestimation if sampled every $15 \mathrm{~min}$. Therefore, adjusting for $15 \%$ underestimation would match the gauge and the radar observed peak STP. We refer to the article by Petersen et al. (1999) for a detailed discussion of the radar data during this event.

\section{Summary and conclusions}

Polarimetric radar rainfall algorithms currently in use are derived assuming equilibrium shape-size relationships. Previous research (e.g., Goddard and Cherry 1984; Beard 1984) as well as more recent studies have indicated potential bias in rainfall estimates due to variability in the shape-size relations. This paper presents polarimetric rainfall algorithms that are immune to variability in shape-size relation. Theoretical analysis was used to demonstrate that conventional polarimetric radar algorithms will be biased due to deviation of shapesize relation from equilibrium shapes. The bias was studied as a function of the slope $(\beta)$ of a linear shapesize relationship for raindrops. When $\beta<\beta_{e}, R\left(Z_{h}, Z_{\mathrm{dr}}\right)$ overestimates the rain rate whereas $R\left(K_{\mathrm{dp}}\right)$ underestimates it. When $\beta>\beta_{e}, R\left(Z_{h}, Z_{\mathrm{dr}}\right)$ underestimates the rain rate whereas $R\left(K_{\mathrm{dp}}\right)$ overestimates it. $R\left(K_{\mathrm{dp}}, Z_{\mathrm{dr}}\right)$ is less sensitive to $\beta$ compared to the other two algorithms. Polarimetric rainfall algorithms $R\left(Z_{h}, Z_{\mathrm{dr}}\right), R\left(K_{\mathrm{dp}}\right)$, and $R\left(K_{\mathrm{dp}}, Z_{\mathrm{dr}}\right)$ were derived for different $\beta$ varying between 0.02 and 0.1 . This analysis was used to demonstrate the sensitivity of the coefficients in these polarimetric rainfall algorithms. This information was used, in turn, to refine the algorithms to adjust themselves for varying shape-size relation for raindrops as well as the polarimetric radar rainfall algorithms. The algorithms developed in this paper were evaluated in the presence of varying shape-size relations, and were found to be immune to these variabilities. In addition, some commonly used shape-size relations are nonlinear. The rainfall algorithms were applied under both the Beard and Chuang (1987) as well as the Andsager et al. (1999) models for raindrop shapes, and simulations were used to demonstrate the success of these algorithms. Subsequently, the sensitivity and robustness of these algorithms to biases and random measurement errors were studied. It was found that the accuracy of the rainfall algorithms was not significantly compromised due to measurement errors. Bias in measurement of $Z_{h}$ and $Z_{\mathrm{dr}}$ affected all three rain-rate estimates $R_{\beta}\left(Z_{h}, Z_{\mathrm{dr}}\right), R_{\beta}\left(K_{\mathrm{dp}}\right)$, as well as $R_{\beta}\left(K_{\mathrm{dp}}, Z_{\mathrm{dr}}\right)$. However, if the bias in $Z_{\mathrm{dr}}$ is less than 0.3 $\mathrm{dB}$ and the bias in $Z_{h}$ is less than $1 \mathrm{~dB}$, then rain-rate estimates were not significantly affected.

A total of six algorithms, namely, $R\left(Z_{h}, Z_{\mathrm{dr}}\right), R\left(K_{\mathrm{dp}}\right)$, $R\left(K_{\mathrm{dp}}, Z_{\mathrm{dr}}\right)$ obtained for the PB model, as well as the algorithms developed in this paper that are immune to variability in $\beta$, namely, $R_{\beta}\left(Z_{h}, Z_{\mathrm{dr}}\right), R_{\beta}\left(K_{\mathrm{dp}}\right)$, and

FIG. 10. (a) The contour of storm total precipitation $(\mathrm{mm})$ computed by $R\left(K_{\mathrm{dp}}\right)$ based on the PB model [40.5( $\left.\left.K_{\mathrm{dp}}\right)^{0.85}\right]$, from CSU-CHILL radar observations for the $28 \mathrm{Jul} 1997$ flood event. (b) The contour of storm total precipitation (mm) computed by $R_{\beta}\left(K_{\mathrm{dp}}\right)$ from CSU-CHILL radar observations for the 28 Jul 1997 flood event. 
$\operatorname{Rdr}$
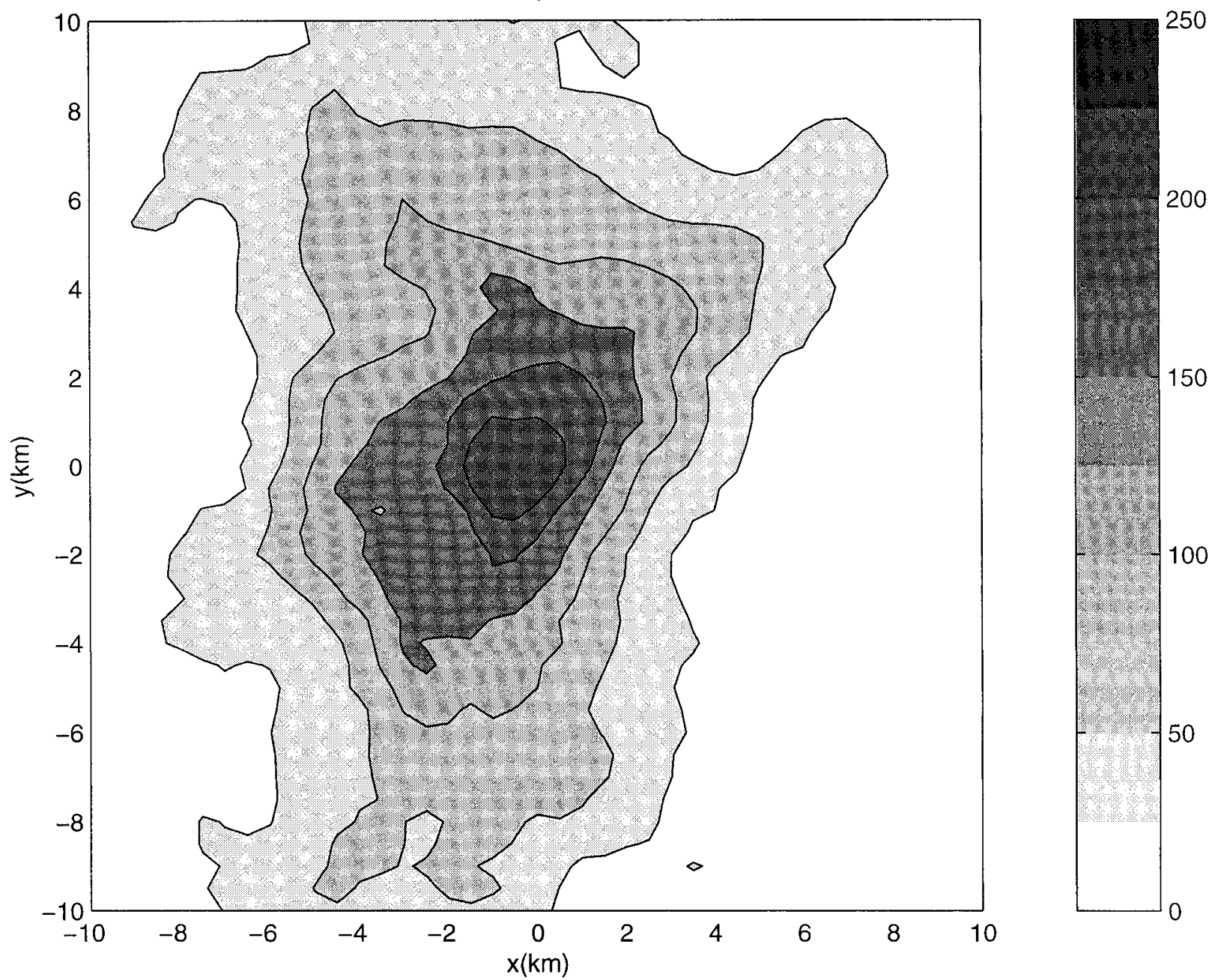

FIG. 11. The contour of storm total precipitation (mm) computed by $R_{\beta}\left(Z_{h}, Z_{\mathrm{dr}}\right)$ from CSU-CHILL radar observations for the 28 Jul 1997 flood event.

$R_{\beta}\left(K_{\mathrm{dp}}, Z_{\mathrm{dr}}\right)$, were evaluated, using disdrometer as well as radar and gauge comparison. Disdrometer evaluation of the composite algorithms developed in this paper showed that they perform well, with low standard error. The composite algorithms $R_{\beta}\left(Z_{h}, Z_{\mathrm{dr}}\right), R_{\beta}\left(K_{\mathrm{dp}}\right), R_{\beta}\left(K_{\mathrm{dp}}\right.$, $Z_{\mathrm{dr}}$ ) were applied to $Z_{h}, Z_{\mathrm{dr}}$, and $K_{\mathrm{dp}}$ simulated from disdrometer observations using the ABL model for raindrop shape. The simulation results showed that all three composite algorithms estimated rainfall fairly accurately, demonstrating the performance of the algorithms for observed raindrop size distributions. Among the three algorithms, $R_{\beta}\left(K_{\mathrm{dp}}, Z_{\mathrm{dr}}\right)$ yielded the lowest error. In addition, the application of rainfall algorithms based on the PB model resulted in significant errors as expected.

Petersen et al. (1999) applied the commonly used $R\left(K_{\mathrm{dp}}\right)=40.5\left(K_{\mathrm{dp}}\right)^{0.85}$ algorithm derived under the assumption of the PB model to estimate storm total precipitation for the 28 July 1997 Fort Collins flood event and found a significant underestimate in the peak ac- cumulation when compared to rain gauge data. This underestimate was due to an unusual tropical type environment that could have resulted in drop oscillation resulting in departure from the equilibrium shape of raindrops. The composite algorithms developed in this paper were found to eliminate the bias caused by the PB model. Application of the composite algorithms to the Fort Collins flood data resulted in a substantial reduction of the difference between the radar and gauge estimates of peak storm total precipitation, demonstrating the potential of the algorithms developed in this paper. In summary, the composite algorithms developed in this paper estimate rainfall without fixing a specific a priori shape-size relation for raindrops, and allowing it to have a general linear form whose slope can be variable.

Acknowledgments. The CSU-CHILL radar is supported by the National Science Foundation (ATM- 
$\operatorname{Rdz}$
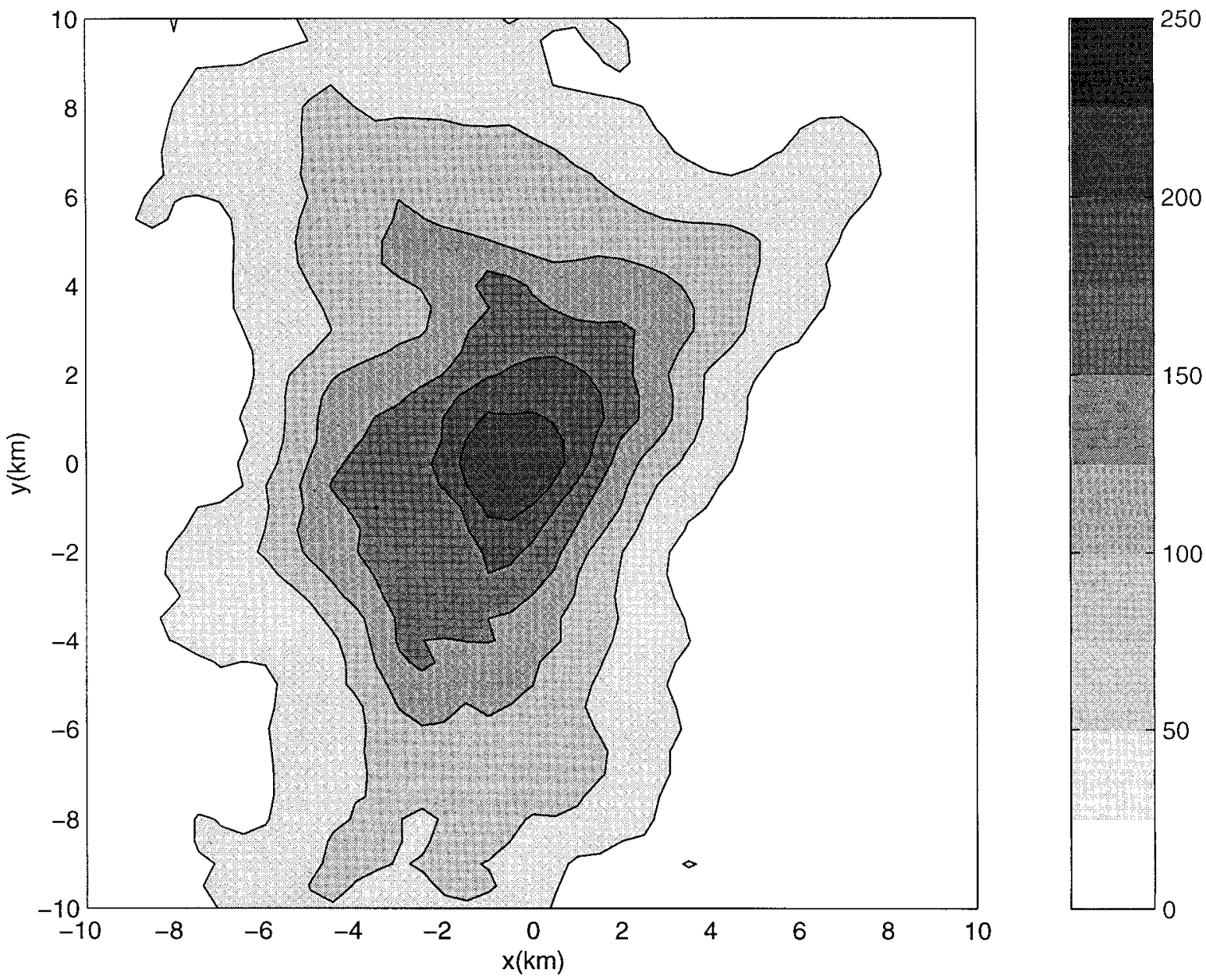

FIG. 12. The contour of storm total precipitation $(\mathrm{mm})$ computed by $R_{\beta}\left(K_{\mathrm{dp}}, Z_{\mathrm{dr}}\right)$ from CSU-CHILL radar observations for the 28 Jul 1997 flood event.

9500108). This research was supported partially by the National Group for Defense from Hydrological Hazard (CNR, Italy), by Progetto Strategico Mesoscale Alpine Program (CNR, Italy), by the Italian Space Agency (ASI). Two of the authors (VC and VNB) acknowledge support from the NASA TRMM program. The disdrometer data were provided by Dr. T. Keenan of the Bureau of Meteorology Research Center. The authors are grateful to A. Mura and P. Iacovelli for assistance rendered during the preparation of the manuscript.

\section{REFERENCES}

Abramovitz, M., and A. Stegun, 1970: Handbook of Mathematical Functions. Dover, 1043 pp.

Andsager, K., K. V. Beard, and N. F. Laird, 1999: Laboratory measurements of axis ratios for large raindrops. J. Atmos. Sci., 56, 2673-2683.

Beard, K. V., 1984: Oscillation modes for predicting raindrop axis and backscatter ratios. Radio Sci., 19, 67-74.

-, and C. Chuang, 1987: A new model for the equilibrium shape of raindrops. J. Atmos. Sci., 44, 1509-1524.
Bringi, V. N., V. Chandrasekar, and R. Xiao, 1998: Raindrop axis ratio and size distributions in Florida rainshafts: An assessment of multiparameter radar algorithms. IEEE Trans. Geosci. Remote Sens., 36, 703-715.

Chandrasekar, V., V. N. Bringi, and P. J. Brockwell, 1986: Statistical properties of dual polarized radar signals. Preprints, 23d Conf. on Radar Meteorology, Snowmass, CO, Amer. Meteor. Soc., $154-157$.

— W. W. Cooper, and V. N. Bringi, 1988: Axis ratios and oscillations of raindrops. J. Atmos. Sci., 45, 1325-1333.

— - V. N. Bringi, N. Balakrishnan, and D. S. Zrnić, 1990: Error structure of multiparameter radar and surface measurements of rainfall. Part III: Specific differential phase. J. Atmos. Oceanic Technol., 7, 621-629.

Doviak, R. J., V. Bringi, A. V. Ryzhkov, A. Zahrai, and D. S. Zrnić, 2000: Consideration for polarimetric upgrades to operational WSR-88D radars. J. Atmos. Oceanic Technol., 17, 257-278.

Goddard, J. W. F., and S. M. Cherry, 1984: The ability of dualpolarization radar (copolar linear) to predict rainfall rate and microwave attenuation. Radio Sci., 19, 201-208.

Gorgucci, E., and G. Scarchilli, 1997: Intercomparison of multiparameter radar algorithms for estimating rainfall rate. Preprints, 28 th Conf. on Radar Meteorology, Austin, TX, Amer. Meteor. Soc., 55-56.

_,$\ldots$, and V. Chandrasekar, 1994: A robust estimator of rainfall 
rate using differential reflectivity. J. Atmos. Oceanic Technol., 11, 586-592.

, and - 1995: Radar and surface measurements of rainfall during CaPE: 26 July 1991 case study. J. Appl. Meteor., 34, 1570-1577.

,,$---\longrightarrow$, and V. N. Bringi, 2000a: Measurement of mean raindrop shape from polarimetric radar observation. J. Atmos. Sci., 57, 3406-3413.

,$- \ldots$, and $-2000 \mathrm{~b}$ : Sensitivity of multiparameter radar rainfall algorithms. J. Geophys. Res., 105, 2215-2223.

Green, A. W., 1975: An approximation for the shapes of large raindrops. J. Appl. Meteor., 14, 1578-1583.

Illingworth, J. I., and T. M. Blackman, 1999: The need to normalize RSDs based on the gamma RSD formulations and implications for interpreting polarimetric radar data. Preprints, 29th Conf. on Radar Meteorology, Montreal, QC, Canada, Amer. Meteor. Soc., 629-631.

Jameson, A. R., 1983: Microphysical interpretation of multiparameter radar measurements in rain. Part I: Interpretation of polarization measurements and estimation of raindrop shapes. J. Atmos. Sci., 40, 1792-1802.

_ 1985: Microphysical interpretation of multiparameter radar measurements in rain. Part III: Interpretation and measurement of propagation differential phase shift between orthogonal linear polarizations. J. Atmos. Sci., 42, 607-614.

- 1991: Polarization radar measurements in rain at 5 and $9 \mathrm{GHz}$. J. Appl. Meteor., 30, 1500-1513.

Joss, J., and A. Waldvogel, 1967: A raindrop spectrograph with automatic analysis. Pure Appl. Geophys., 68, 240-246.

Keenan, T. D., P. T. May, D. S. Zrnić, L. D. Carey, and S. A. Rutledge, 1997: Sensitivity of C-band polarimetric variables to propagation and backscatter effects in rain. Preprints, 28th Conf. on Radar Meteorology, Austin, TX, Amer. Meteor. Soc., 13-14.

Petersen, A. P., and Coauthors, 1999: Mesoscale and radar observations of the Fort Collins flash flood of 28 July 1997. Bull. Amer. Meteor. Soc., 80, 191-216.

Pruppacher, H. R., and K. V. Beard, 1970: A wind tunnel investigation of the internal circulation and shape of water drops falling at terminal velocity in air. Quart. J. Roy. Meteor. Soc., 96, 247256.

_- - and J. D. Klett, 1997: Microphysics of Cloud and Precipitation. $2 \mathrm{~d}$ ed. Kluwer Academic, 955 pp.

Ryzhkov, A. V., and D. S. Zrnić, 1995: Comparison of dual-polarization radar estimators of rain. J. Atmos. Oceanic Technol., 12, 249-256.

Sachidananda, M., and D. S. Zrnić, 1987: Rain rate estimates from differential polarization measurements. J. Atmos. Oceanic Technol., 4, 588-598.

Seliga, T. A., and V. N. Bringi, 1976: Potential use of the radar reflectivity at orthogonal polarizations for measuring precipitation. J. Appl. Meteor., 15, 69-76.

$\ldots$, and ——, 1978: Differential reflectivity and differential phase shift: Applications in radar meteorology. Radio Sci., 13, 271275.

Testud, J., E. L. Bouar, E. Obligis, and M. Ali-Mehenni, 2000: The rain profiling algorithm applied to polarimetric weather radar. $J$. Atmos. Oceanic Technol., 17, 332-356.

Ulbrich, C. W., 1983: Natural variations in the analytical form of raindrop size distributions. J. Climate Appl. Meteor., 22, 17641775.

Willis, P. T., 1984: Functional fits to some observed drop size distribution and parameterization of rain. J. Atmos. Sci., 41, 16481661 . 